\title{
O NOVO FUNDEB E O DEVER DE PROGRESSIVIDADE NA CONCRETIZAÇÃO DO DIREITO À EDUCAÇÃO BÁSICA: UM ESTUDO HISTÓRICO- COMPARATIVO DOS FUNDOS DE FINANCIAMENTO
}

Resumo: A pesquisa apresenta o Novo FUNDEB, instituído pela Emenda Constitucional 108/2020, como instrumento de concretização do direito à educação básica. Tem o objetivo de avaliar, com base no conceito de progressividade disposto no PIDESC, se houve avanços em relação aos antecessores desse fundo de financiamento, a saber o FUNDEF e o FUNDEB (em sua primeira edição). Utiliza o método de abordagem dedutivo e, como métodos de procedimento, o histórico e o comparativo, para concluir que o Novo FUNDEB apresenta aspectos que revelam sua progressividade em relação aos fundos anteriores.

Palavras-chave: Progressividade. Direito à educação. Educação Básica. Financiamento. Novo FUNDEB.

\section{NEW FUNDEB AND THE DUTY OF PROGRESSIVITY IN THE REALIZATION OF THE RIGHT TO BASIC EDUCATION: A HISTORICAL-COMPARATIVE STUDY OF FUNDING FUNDS}

\begin{abstract}
The research presents the New FUNDEB, instituted by the Constitutional Amendment 108/2020, as an instrument to materialize the right to basic education. Its purpose is to evaluate, based on the concept of progressivity set forth in the ICESCR, whether there have been advances in relation to the predecessors of this funding fund, namely FUNDEF and FUNDEB (in its first edition). It uses the deductive method and, as procedure methods, the historical and comparative, to conclude that the New FUNDEB presents aspects that reveal its progressivity in relation to previous funds.
\end{abstract}

Keywords: Progressivity. Right to education. Basic education. Financing. Novo FUNDEB.

\section{INTRODUÇÃO}

O financiamento da educação básica pública é tema que está na ordem do dia dos debates sobre a concretização do direito fundamental social à educação no Brasil, principalmente em face da aprovação do novo Fundo de Manutenção e Desenvolvimento da

\footnotetext{
* Doutorando em Direito (Unisinos). Mestre e Bacharel em Direito (UFPel). Licenciado em Letras (UFPel). Auditor-geral no Instituto Federal de Educação, Ciência e Tecnologia Sul-rio-grandense (IFSul).
} 
Educação Básica e de Valorização dos Profissionais da Educação (Novo FUNDEB), promulgado pela Emenda Constitucional n. 108, de 26 de agosto de 2020.

O presente artigo tem o objetivo de avaliar, com base no conceito de progressividade disposto no Pacto Internacional sobre Direitos Econômicos, Sociais e Culturais (PIDESC), se houve avanços em relação aos antecessores desse fundo de financiamento, a saber o Fundo de Manutenção e Desenvolvimento do Ensino Fundamental e de Valorização do Magistério (FUNDEF) e a primeira edição do FUNDEB.

Para isto, será empregado o método dedutivo, avaliando a trajetória de progressividade em matéria de financiamento das políticas voltadas a atender o direito à educação básica. Os métodos de procedimento serão o histórico e o comparativo: o primeiro será empregado na construção de uma linha do tempo que abrangerá os três Fundos e o segundo, na comparação entre eles, dentro da mesma linha evolutiva.

O artigo será dividido em três seções: a primeira abordará o dever de progressividade dos Estados na concretização dos direitos fundamentais sociais, a partir do PIDESC; a segunda apresentará o FUNDEF e o FUNDEB (em sua primeira versão), numa perspectiva comparativa; a terceira e última, descreverá as principais regras veiculadas pelo Novo FUNDEB, comparando-as com as normas vigentes até o final de 2020.

$\mathrm{Na}$ conclusão, será realizada uma breve análise da trajetória evolutiva dos três Fundos, tendo como parâmetro o dever de progressividade na concretização do direito fundamental social à educação, notadamente a educação básica.

\section{O DEVER DE PROGRESSIVIDADE NA CONCRETIZAÇÃO DOS DIREITOS FUNDAMENTAIS SOCIAIS}

Abordar algum direito fundamental social remete necessariamente a sua previsão normativa, que se estende a partir dos instrumentos de direito internacional até a legislação ordinária, passando pela Constituição. $\mathrm{O}$ arcabouço legislativo pátrio necessita ofertar o lastro sobre o qual se edificará a concretização de cada um desses direitos.

Não obstante, a discussão sobre esses direitos irá extrapolar a esfera do Estado Nacional. A Constituição Federal, no par. $2^{\circ}$ do art. $5^{\circ}$, reforça que os direitos fundamentais expressamente elencados nesse artigo não constituem um rol taxativo, mas podem ser ampliados para outros decorrentes do regime e dos princípios por ela adotados, além daqueles 
introduzidos pelos tratados internacionais assinados pelo Brasil. É a esse fenômeno que Sarlet (2018) se refere como a abertura do catálogo de direitos fundamentais.

Um desses instrumentos de direito internacional que veicula conteúdos fundamentais é o PIDESC, que aponta o dever de progressividade dos direitos sociais como uma das obrigações genéricas dos Estados signatários, além da obrigação de adoção de medidas imediatas e de assegurar níveis essenciais desses direitos (ABRAMOVICH; COURTIS, 2011). O Pacto, no artigo 2.1, estabelece o compromisso dos Estados signatários de promover medidas progressivas, até o limite dos recursos disponíveis, para garantir o pleno exercício dos direitos nele previstos, inclusive mediante a adoção de medidas legislativas. Dessa implementação progressiva dos direitos econômicos, sociais e culturais, é possível extrair dois sentidos: a melhoria contínua do gozo dos direitos por parte dos indivíduos e a vedação, ao Estado, de adotar medidas deliberadamente regressivas (SEPÚLVEDA, 2006).

O primeiro sentido refere-se à gradualidade, que pressupõe que tais direitos não podem ser alcançados em curto período de tempo, em razão das dificuldades naturais enfrentadas pelos Estados na sua implementação, motivo pelo qual é um mecanismo sensível. O outro é o do progresso, que exige dos Estados providências destinadas a assegurar as condições de exercício e gozo desses direitos tão rapidamente quanto possível (COURTIS, 2006; ABRAMOVICH; COURTIS, 2011).

O reverso da obrigação de implantação progressiva dos direitos econômicos, sociais e culturais, assegurada no PIDESC, é o dever de não regressividade (KARNOPP, 2020), tendo em vista que a obrigação dos Estados é sempre ampliativa e, por consequência, a derrogação ou diminuição dos direitos vigentes afronta o compromisso internacional assumido. Esse dever de não regressividade, no entendimento de Abramovich e Courtis (2011, p. 117-118), pode ser revisto judicialmente em caso de descumprimento:

\footnotetext{
A obrigação mínima assumida pelo Estado a respeito é a obrigação de não regressividade, ou seja, a proibição de adotar políticas, medidas e, por conseqüência, sancionar normas jurídicas que piorem a situação dos direitos econômicos, sociais e culturais dos que usufruía a população no momento da adoção do respectivo tratado internacional ou também em cada melhora "progressiva". Dado que o Estado se obriga a melhorar a situação destes direitos, simultaneamente assume a proibição de reduzir os níveis de proteção dos direitos vigentes ou, por outro lado, de derrogar os direitos já existentes. A obrigação assumida pelo Estado é ampliativa, de modo que a derrogação ou redução dos direitos vigentes contradiz frontalmente o compromisso internacional assumido.
} 
A Convenção Americana sobre Direitos Humanos, assim como o PIDESC, carreia aos Estados a proibição de regressividade como obrigação genérica. Courtis (2006, p. 15) assinala que

\begin{abstract}
De acuerdo com el artículo 2, los Estados que [?] hayan garantizado legislativamente o a través de medidas de otro carácter el ejercicio de los derechos estabelecidos en la Convención, tienen el deber de hacerlo. Pero esto implica, a su vez, la prohibición de medidas que deroguen o eliminen la legislación u otras disposiciones necesarias para el ejercicio de los derechos reconocidos en ese instrumento. Esto significa la consagración de la prohibición de regresividad normativa, al menos en la medida em que esa regresión afecte las normas y disposiciones necesarias para el ejercicio de los derechos de la Convención.
\end{abstract}

Verifica-se que se trata de uma proibição de regressividade normativa (COURTIS, 2006), pois diz respeito a providências legislativas de âmbito doméstico. Abramovich e Courtis (2011) ensinam que os Estados estão impedidos de derrogar ou suspender a legislação que já assegura algum direito, ou mesmo de adotar legislação incompatível com aquela já existente ou adotar outra medida que diminua a garantia do direito.

Desse modo, ao legislador se impõe que concretize progressivamente os direitos fundamentais, aprimorando seu usufruto por parte dos cidadãos. Nesse sentido, Sarlet (2018, p. 384) defende que

\begin{abstract}
em nosso direito constitucional, o postulado da aplicabilidade imediata dos direitos fundamentais (art. $5^{\circ}, \S 1^{\circ}$, da $\mathrm{CF}$ ) pode ser compreendido como um mandado de otimização de sua eficácia, pelo menos no sentido de impor aos poderes públicos a aplicação imediata dos direitos fundamentais, outorgando-lhes, nos termos desta aplicabilidade, a maior eficácia possível. Assim, por exemplo, mesmo em se tratando de norma de eficácia inequivocamente limitada, o legislador, além de obrigado a atuar no sentido da concretização do direito fundamental, encontra-se proibido (e nesta medida também está vinculado) de editar normas que atentem contra o sentido e a finalidade da norma de direito fundamental.
\end{abstract}

A atuação do legislador remete a uma das obrigações genéricas impostas aos Estados pelo PIDESC, qual seja a obrigação de adequação do marco legal (ABRAMOVICH; COURTIS, 2011). Logo, a atuação legislativa estatal deve estar pautada no dever de progressividade sinalado pelo PIDESC e voltada à concretização dos direitos fundamentais sociais. 
A partir do dever de progressividade assumido pelo Estado brasileiro, é possível analisar como se deu o percurso histórico do FUNDEB e indagar em que direção caminhou, se houve avanços e quais foram.

\section{O FUNDEB E O FINANCIAMENTO DA EDUCAÇÃO BÁSICA NUMA PERSPECTIVA HISTÓRICA E CONCEITUAL}

O direito fundamental social à educação, o qual constitui um dever de prestação por parte do Estado, demanda custos - razão pela qual é denominado, também, como um direito econômico. Nesse ponto, é que cabe apresentar e descrever o instrumento de custeio das políticas públicas educacionais consistente no FUNDEB.

O FUNDEB veio em substituição ao anterior FUNDEF, previsto pelo art. 60, par. $1^{\circ}$, do Ato das Disposições Constitucionais Transitórias (ADCT), conforme redação determinada pela Emenda Constitucional n. 14, de 12 de setembro de 1996, com previsão de vigência de 10 anos.

Anteriormente ao FUNDEF, a Constituição Federal, no art. 212, caput, já determinava a destinação, por parte dos Estados e dos Municípios, de 25\% das receitas arrecadadas com impostos e transferências à manutenção e desenvolvimento do ensino. A Emenda Constitucional n. 14/1996, ao criar o Fundo, estabeleceu que $60 \%$ desse montante passaria a ser de destinação obrigatória ao custeio do ensino fundamental, para universalizar seu atendimento e remunerar o magistério, o que representa, no total, 15\% dos recursos provenientes de impostos e transferências.

A redação conferida ao art. 60 do ADCT pela Emenda Constitucional n. 14/1996 veio outorgar maior efetividade ao dispositivo em comparação ao texto antigo. Anteriormente, na redação original, o art. 60 determinava a destinação de metade dos recursos do art. 212, caput, da Constituição Federal à eliminação do analfabetismo e à universalização do ensino fundamental. A norma não atingiu a eficácia esperada, conforme esclarece Nunes (2016, p. 22-23):

o dever constitucional de prestar o direito à educação, aliado à vinculação de recursos, não promoveu, por si só, cenário favorável à universalização do ensino e progressão de sua qualidade. Na prática, os entes subnacionais tiveram dificuldade em atender à demanda que quadruplicara entre 1940 e 1970 (ROMANELLI apud SANO, 2008, p. 168), somada às lacunas deixadas pela desvinculação de recursos da 
Constituição anterior. Além disso, a vinculação condicionava-se à arrecadação dos entes federativos, o que gerava disparidades na alocação de recursos educacionais entre entes que mais arrecadavam frente aos que arrecadavam em menor volume. Tal fato agravava ainda mais a desigualdade entre regiões do país.

A Emenda Constitucional n. 14/1996, portanto, foi uma resposta aos desafios financeiros opostos ao Estado brasileiro diante dos seus deveres relativos à prestação de políticas educacionais, mediante a criação do FUNDEF, fundo de natureza contábil, destinado a "subvincular parte dos recursos já vinculados, determinando a alocação, e prevendo maior valorização da classe do professorado" (NUNES, 2015, p. 76).

Para regulamentar o FUNDEF, a Lei n. 9.424, de 24 de dezembro de 1996, estabeleceu que este teria implantação automática a partir de $1^{\circ}$ de janeiro de 1998 , com vigência por dez anos. Além disso, fixou os critérios de composição desse Fundo, de distribuição de recursos e, até mesmo, de controle social de sua aplicação, para evitar desvios ou má alocação.

Quanto à composição, o Fundo era formado basicamente por recursos dos Estados e dos Municípios, a saber, de acordo com a lei instituidora, por 15\% das seguintes fontes: Imposto sobre a Circulação de Mercadorias e Serviços (ICMS) de transporte interestadual e intermunicipal e de comunicação, inclusive receitas decorrentes da desoneração das exportações (Lei Complementar n. 87/1996); Fundo de Participação dos Estados e do Distrito Federal (FPE); Fundo de Participação dos Municípios (FPM); Imposto sobre Produtos Industrializados (IPI), proporcional às exportações. A complementação de recursos pela União aconteceria no caso de o valor por aluno não alcançar o mínimo definido nacionalmente, no âmbito de cada Estado e do Distrito Federal.

A União exercia papel apenas supletivo na composição do Fundo, tendo em vista que complementaria o montante somente se o valor por aluno não alcançasse o nacionalmente definido, em cada Estado ou Distrito Federal.

A distribuição dos recursos do FUNDEF passou a ser realizada com base na quantidade de estudantes de ensino fundamental, conforme dados do Censo Escolar, levantamento realizado pelo Instituto Nacional de Estudos e Pesquisas Educacionais Anísio Teixeira (INEP), o qual, de acordo com Gonzaga (2017), é o mais relevante instrumento de coleta de informações sobre a educação básica brasileira, reunindo dados sobre estabelecimentos de ensino, alunos e professores. 
Assim, a distribuição dos recursos do FUNDEF, em cada Estado da federação "se dava entre o Estado e seus municípios, na direta proporção do número de alunos matriculados no ensino fundamental nas escolas de cada rede de ensino, com base nas matrículas iniciais computadas pelo censo do MEC do ano anterior" (RAMOS; DI GIORGI, 2011, p. 629).

Nessa linha, Nunes (2016, p. 23) esclarece que

Esse sistema de financiamento, em comparação com a mera vinculação das receitas de impostos, permitiu mudança de paradigma com relação às despesas educacionais, cuja obtenção de recursos passou a ter como variável o número de matriculados na rede. Assim, quanto maior a rede, mais recursos; e vice-versa.

Portanto, o FUNDEF representou um passo à frente na destinação de recursos às políticas públicas voltadas à efetivação do direito fundamental social à educação, levando-o a um maior nível de concretização.

Ainda quanto à destinação dos recursos do FUNDEF, importa destacar que, no tocante à valorização dos profissionais do magistério, a Lei n. 9.424/1996 estabelecia que no mínimo $60 \%$ dos recursos do Fundo seriam destinados, necessariamente, à remuneração dos profissionais do magistério (embora a Constituição Federal se refira somente à remuneração dos professores do ensino fundamental). A valorização dos profissionais da educação escolar é princípio inscrito na Constituição Federal (art. 206, V) e, ainda, na Lei n. 9.394/1996 (art. 67), conhecida como Lei de Diretrizes e Bases da Educação Nacional (LDBEN). Por conseguinte, a destinação de parcela do Fundo à remuneração desses profissionais vem ao encontro desse princípio e representa um importante passo na sua valorização.

Apesar dos avanços instituídos pelo FUNDEF, percebeu-se a necessidade de aprimoramentos, tendo em vista que a vigência do Fundo estava prevista para 2006 e que este não abrangia a educação infantil, o ensino médio e a educação de jovens e adultos. Ademais, faltavam aportes adicionais significativos por parte da União, que não contribuiu suficientemente ao longo da vigência do Fundo (GONZAGA, 2017).

Gonzaga (2017, p. 53) aponta para outros problemas observados durante a vigência do FUNDEF:

Além da necessidade de ampliação para toda educação básica e vigência até o ano de 2006, alguns problemas foram observados ao longo dos, aproximados, 10 anos de Fundef, por exemplo, expansão extraordinária e descontrolada de matrículas ignorando idade (CÂMARA DOS DEPUTADOS FEDERAIS, GASTÃO VIEIRA, 2005); problemas de fiscalização dos recursos, com estruturas de poder social com 
instituições aparelhadas por prefeito local, não existindo "controle social verdadeiro, e sim uma cumplicidade política" (CÂMARA DOS DEPUTADOS FEDERAIS, TARSO GENRO, 2005, p. 12); fraudes no censo escolar, com informações de matrículas de alunos inexistentes no ensino fundamental no intuito de receber mais recursos do Fundo.

Diante das insuficiências apresentadas pelo modelo do FUNDEF, foi necessário pensar em outro fundo para substituí-lo no término da sua vigência. Já no início do primeiro mandato do Presidente Luís Inácio Lula da Silva, em 2003, foi instituído um grupo de trabalho para realizar essa discussão.

Sobre a atuação do grupo de trabalho instituído no Governo Lula, Nunes (2016, p. 26) narra que

\begin{abstract}
O debate que se seguiu à criação do Grupo de Trabalho concentrou-se no tema do aporte de recursos que o governo federal deveria estender ao Fundo. Ao abarcar todas as etapas do ensino básico, requeria-se também mais recursos, e a União buscou garantir recursos suficientes para cumprir com as obrigações que a Emenda viria estabelecer. Discutia-se, também, a vedação da desvinculação de recursos educacionais da União, tal como previsto pela DRU.

No entanto, o pedido de extinção da DRU para o financiamento da educação não era um entendimento uníssono dentro do governo; pelo contrário, havia certa divergência entre o Ministério da Fazenda e Ministério da Educação: o primeiro entendia que poderia haver sacrifício das contas federais, frustrando outras despesas públicas; já o MEC defendia a manutenção do sistema vinculatório de recursos federais em sua integralidade, o que garantiria a existência de recursos para prestar o serviço.
\end{abstract}

Além da atuação do grupo de trabalho criado para essa finalidade, houve mobilização da sociedade civil e de entidades como o Conselho Nacional de Secretários de Educação (CONSED) e a União Nacional dos Dirigentes Municipais de Educação (UNDIME), o que permitiu um amplo diálogo sobre a instituição do fundo sucessor. A sociedade civil, por meio da Campanha Nacional do Direito à Educação, coordenou o movimento Fundeb pra valer Direito à educação começa no berço e é pra toda vida, o qual defendia a inclusão das creches no financiamento a ser promovido pelo próximo fundo (NUNES, 2016).

Gonzaga (2017) recorda que a campanha política que levou o Presidente Lula à Presidência da República abarcava um programa de governo que estimulava a ampliação progressiva de investimentos em educação, da creche à pós-graduação. Esse programa

Tinha como meta promover a educação infantil a um novo estatuto; universalizar o ensino do nível pré-escolar até o médio e garantir o acesso à creche; formular uma política para inclusão dos jovens trabalhadores no ensino médio; ampliar vagas nas 
universidades públicas e reformular o sistema de crédito educativo (GONZAGA, 2017, p. 54).

Em virtude dessas metas que ultrapassavam o estímulo à universalização do ensino fundamental, justificava-se a ampliação do FUNDEF para abranger, também, os demais níveis da educação básica, bem como assegurar maior participação da União no seu financiamento, já que era tímida a contribuição desse ente federativo em termos de recursos financeiros.

Após todos os estudos promovidos inicialmente pelo grupo de trabalho instituído para essa finalidade específica e ultimada toda tramitação legislativa, a Emenda Constitucional n. 53, de 19 de dezembro de 2006, criou o FUNDEB, estabelecendo sua vigência até o ano de 2020. Conforme previsto, o novo Fundo passou a abranger todos os níveis da educação básica e a ostentar regras mais específicas sobre a participação da União na complementação dos recursos (NUNES, 2016).

O novo Fundo foi regulamentado pela Medida Provisória n. 339, de 28 de dezembro de 2006, convertida na Lei n. 11.494, de 20 de junho de 2007.

A Emenda Constitucional n. 53/2006 alterou o art. 60 do ADCT para criar, no âmbito de cada Estado e do Distrito Federal, de um fundo de natureza contábil, composto por parte dos recursos estabelecidos no caput do art. 212 da Constituição Federal. De acordo com esse dispositivo, o FUNDEB é composto de $20 \%$ das receitas dos seguintes impostos e transferências constitucionais: Imposto sobre Transmissão de Causa Mortis ou Doação (ITCMD), Imposto sobre Circulação de Mercadorias e Serviços (ICMS) e Imposto sobre Propriedade de Veículos Automotores (IPVA), arrecadados pelos Estados e Distrito Federal; imposto residual da União, o qual ainda não foi criado; parcela do Imposto Territorial Rural (ITR), do IPVA e do ICMS pertencente aos municípios; parcela do Imposto sobre a Renda (IR) e do Imposto sobre Industrialização (IPI) devido ao FPE e ao FPM; parcela do IPI proporcional às exportações dos Estados.

Nunes (2015, p. 78) apresenta o seguinte quadro, que detalha a origem dos recursos financeiros que compõem o FUNDEB:

\section{Quadro 1 - Recursos que compõem o FUNDEB}

\begin{tabular}{|l|l|}
\hline \multicolumn{1}{|c|}{ Tributo } & \multicolumn{1}{|c|}{ Origem } \\
\hline Imposto sobre transmissão causa mortis e doação (ITCMD) & Arrecadação do Estado \\
\hline $\begin{array}{l}\text { Imposto sobre operações relativas à circulação de mercadorias e sobre } \\
\text { prestações de serviços de transportes interestadual e intermunicipal e de }\end{array}$ & $\begin{array}{l}\text { Arrecadação do Estado e parte } \\
\text { da transferência obrigatória do }\end{array}$ \\
\hline
\end{tabular}




\begin{tabular}{|c|c|}
\hline comunicação (ICMS) & Estado ao Município \\
\hline Imposto sobre a propriedade de veículos automotores (IPVA) & $\begin{array}{l}\text { Arrecadação do Estado e parte } \\
\text { da transferência obrigatória do } \\
\text { Estado ao Município }\end{array}$ \\
\hline Parcela de imposto residual da União (não criado) & $\begin{array}{l}\text { Parcela destinada à } \\
\text { transferência da União aos } \\
\text { Estados e Distrito Federal }\end{array}$ \\
\hline Parcela do Imposto sobre a Propriedade Territorial Rural (ITR) & $\begin{array}{l}\text { Transferência da União ao } \\
\text { Município }\end{array}$ \\
\hline $\begin{array}{l}\text { Parcela do Imposto de Renda e Proventos de Qualquer Natureza (IR) e do } \\
\text { Imposto sobre Produtos Industrializados (IPI), devida ao Fundo de } \\
\text { Participação dos Estados e Distrito Federal (FPE) }\end{array}$ & $\begin{array}{l}\text { Transferência da União aos } \\
\text { Estados e Distrito Federal }\end{array}$ \\
\hline $\begin{array}{l}\text { Parcela do Imposto de Renda e Proventos de Qualquer Natureza (IR) e do } \\
\text { Imposto sobre Produtos Industrializados (IPI), devida ao Fundo de } \\
\text { Participação dos Municípios (FPM) }\end{array}$ & $\begin{array}{l}\text { Transferência da União aos } \\
\text { Municípios }\end{array}$ \\
\hline Parcela do Imposto sobre Produtos Industrializados (IPI) & $\begin{array}{l}\text { Transferência da União aos } \\
\text { Estados e Distrito Federal }\end{array}$ \\
\hline $\begin{array}{l}\text { Receitas da dívida ativa tributária relativa aos impost } \\
\text { juros e multas eventualmente incidentes }\end{array}$ & $\begin{array}{l}\text { União, Estados e Distrito } \\
\text { Federal }\end{array}$ \\
\hline
\end{tabular}

Fonte: NUNES, 2015, p. 78.

Sobre a composição desse fundo, a autora pondera:

\begin{abstract}
Nota-se que a cesta de recursos é mais abrangente que a do FUNDEF, que era composta por parcelas do ICMS, FPM e FPE (CF, artigos 155, inciso II; 158, inciso IV; e 159, inciso I, alíneas a e b; e inciso II). Por força dessa mudança, enquanto o FUNDEF tinha encerrado 2006 com R\$ 35,5 bilhões de recursos previstos, o FUNDEB poderia alcançar o montante de $\mathrm{R} \$ 43,1$ bilhões em seu primeiro ano de vigência. $\mathrm{O}$ aumento de recursos estava, assim, intrinsecamente ligado à abrangência do novo Fundo, que abarcava todo o ensino básico, desde as creches até o ensino para jovens e adultos (NUNES, 2016, p. 29).
\end{abstract}

O texto introduzido no ADCT pela Emenda Constitucional n. 53/2006 foi mais claro em relação aos aportes da União no FUNDEB, estabelecendo que, no âmbito de cada Estado em que a arrecadação não fosse suficiente para alcançar o valor mínimo de aluno por ano, haverá a destinação de recursos federais a título de complementação.

Além disso, o texto constitucional passou a estabelecer aportes mínimos pela União no FUNDEB, os quais correspondem a 2 bilhões de reais no primeiro ano de vigência dos Fundos, 3 bilhões de reais no segundo ano e 4,5 bilhões de reais no terceiro ano (todos atualizados anualmente) e, a partir do quarto ano de vigência, $10 \%$ do total de recursos aportados por Estados e Municípios.

O FUNDEB teve implementação gradativa não somente em relação às verbas referentes à complementação federal, mas também quanto aos demais recursos aportados pelos Estados, Distrito Federal e Municípios. O seguinte quadro, transcrito de Gonzaga (2017, 
p. 60), sintetiza o mandamento constitucional quanto aos investimentos oriundos de cada fonte de recursos:

Quadro 2 - Escala de Implantação Financeira do Fundeb

\begin{tabular}{|c|c|c|c|c|c|}
\hline \multirow{2}{*}{ UFs } & \multirow{2}{*}{ Origem dos Recursos } & \multicolumn{4}{|c|}{ Contribuição à Formação do Fundo } \\
\hline & & 2007 & 2008 & 2009 & 2010 a 2020 \\
\hline \multirow{2}{*}{$\begin{array}{l}\text { Estados, } \\
\text { Distrito } \\
\text { Federal } \\
\text { Municípios }\end{array}$} & $\begin{array}{l}\text { FPE, FPM, ICMS, LC 87/96 } \\
\text { e IPIexp (*) }\end{array}$ & $16,66 \%$ & $18,33 \%$ & $20 \%$ & $20 \%$ \\
\hline & $\begin{array}{l}\text { ITCMD, IPVA, ITRm e } \\
\text { outros eventualmente } \\
\text { instituídos }(*)\end{array}$ & $6,66 \%$ & $13,33 \%$ & $20 \%$ & $20 \%$ \\
\hline União & $\begin{array}{l}\text { Complementação Federal } \\
(* *)\end{array}$ & $\begin{array}{c}\text { R\$ } 2 \\
\text { Bilhões }\end{array}$ & $\begin{array}{c}\text { R\$ } 3 \\
\text { Bilhões }\end{array}$ & $\begin{array}{l}\mathrm{R} \$ 4,5 \\
\text { Bilhões }\end{array}$ & $\begin{array}{l}10 \% \text { da } \\
\text { contribuição } \\
\text { total de } \\
\text { Estados, } \\
\text { Distrito } \\
\text { Federal e } \\
\text { Municípios }\end{array}$ \\
\hline
\end{tabular}

(*) Inclusive receitas correspondentes à dívida ativa, juros e multas relacionadas aos respectivos impostos. (**) Valores originais, sem atualização monetária.

Fonte: GONZAGA, 2017, p. 60.

A distribuição dos recursos do FUNDEB, assim como ocorria com o FUNDEF, foi estabelecida com base no Censo Escolar, realizado anualmente pelo INEP. No caso do novo Fundo, foram criados fatores de ponderação, definidos anualmente, de acordo com os seguintes desdobramentos da educação básica: (a) creche pública em tempo integral; (b) creche pública em tempo parcial; (c) creche conveniada em tempo integral; (d) creche conveniada em tempo parcial; (e) pré-escola em tempo integral; (f) pré-escola em tempo parcial; (g) anos iniciais do ensino fundamental urbano; (h) anos iniciais do ensino fundamental no campo; (i) anos finais do ensino fundamental urbano; (j) anos finais do ensino fundamental no campo; (k) ensino fundamental em tempo integral; (l) ensino médio urbano; (m) ensino médio no campo; (n) ensino médio em tempo integral; (o) ensino médio integrado à educação profissional; (p) educação especial; (q) educação indígena e quilombola; (r) educação de jovens e adultos com avaliação no processo; e (s) educação de jovens e adultos integrada à educação profissional de nível médio, com avaliação no processo (BRASIL, 2007).

No tocante à utilização dos recursos, assim como ocorria com o FUNDEF, o ADCT exige a aplicação de no mínimo 60\% (de cada Fundo, em âmbito estadual) para a remuneração de profissionais do magistério da educação básica em efetivo exercício. A Lei n. 11.494/2007 considera como profissionais do magistério os docentes e demais profissionais 
que oferecem suporte pedagógico direto às atividades de docência e como de efetivo exercício aqueles que atuem efetivamente em tais atividades, por vinculação contratual, temporária ou estatutária, com o ente governamental que os remunera. A Lei, por outro lado, nada diz a respeito sobre o emprego do FUNDEB na remuneração de inativos.

Numa comparação entre a estrutura normativa do FUNDEF e do FUNDEB, consideradas as disposições constitucionais e infraconstitucionais, é possível observar a progressividade havida na transição do primeiro para o segundo fundo. Nesse ponto, cabe destacar dois aspectos que assinalam para essa conclusão: a ampliação do atendimento do ensino fundamental para toda a educação básica e a garantia de maior participação da União na composição do Fundo.

O primeiro aspecto harmoniza as políticas públicas educacionais brasileiras com as disposições do PIDESC sobre o direito à educação, as quais dão ênfase à generalização da educação secundária, para torná-la acessível a todos (BRASIL, 1992). Afora isso, a Constituição Federal assegura a progressiva universalização do ensino médio e a educação infantil para crianças com até cinco anos de idade, ofertada em creches e pré-escolas. Expandir o Fundo para o custeio desses níveis de ensino é coerente, portanto, com as disposições do direito internacional e doméstico, que prevê mais do que a garantia do ensino fundamental.

Outro aspecto que revela a progressividade do segundo Fundo em relação ao primeiro, como se disse, foi a maior participação da União no aporte financeiro para o FUNDEB. Ao passo que no FUNDEF esse ente apenas complementava os recursos em caso de não atingimento da média mínima nacional, a legislação do FUNDEB obrigou o aporte de recursos federais, inclusive mediante a fixação de valores e percentuais.

Quanto à remuneração dos profissionais da educação, embora não tenha havido progressividade no percentual destinado pela norma, mantendo-se, no FUNDEB, os mesmos $60 \%$ destinados pelo FUNDEF, ao menos não houve diminuição. É possível afirmar que consignar essa parcela de recursos em ambos os Fundos é condizente com o princípio da valorização dos profissionais do magistério, inscrito tanto na Constituição Federal quanto na LDBEN, razão pela qual apresenta-se como relevante para uma adequada prestação do direito fundamental social à educação pelas escolas públicas. 
Às vésperas do final da vigência do Fundo, foi promulgado o Novo FUNDEB, por meio da Emenda Constitucional n. 108, de 26 de agosto de 2020, ainda pendente de regulamentação. A uma breve análise passar-se-á na seção seguinte.

\section{O NOVO FUNDEB NOS CAMINHOS DA PROGRESSIVIDADE?}

A promulgação da Emenda Constitucional n. 108, que veicula o Novo FUNDEB, pôs fim a um longo processo de discussão entre Governo, Congresso e sociedade civil acerca dos rumos do financiamento da educação pública brasileira. Nesse sentido, merecem ser destacados alguns pontos, ainda que, dada a novidade da referida Emenda Constitucional, não haja, até a finalização deste artigo, lei regulamentadora do Fundo.

O novo texto trouxe profundas e importantes modificações na Constituição Federal e no Ato das Disposições Constitucionais Transitórias (ADCT), advindas pela alteração de dispositivos já existentes e pela inserção de outros.

Inicialmente, cabe assinalar que, apesar de não veicular, em sua maior parte, conteúdo jusfundamental, a Emenda Constitucional n. 108/2020 insere o inciso IX no artigo 206 da Constituição Federal, o qual não segue essa linha. Trata-se da garantia do direito à educação e à aprendizagem ao longo da vida, como princípio do ensino. Esse novo princípio reforça o direito subjetivo de acesso à educação básica obrigatória e gratuita mesmo àqueles que não o tiveram em idade própria (artigo 208, I, da Constituição Federal).

Alterações relevantes foram introduzidas no artigo 212 da Constituição Federal, mediante a criação dos parágrafos $7^{\circ}, 8^{\circ}$ e $9^{\circ}$. Esse artigo estabelece percentuais mínimos de aplicação em manutenção e desenvolvimento do ensino para todos os entes federados, obrigando a União a investir no mínimo $18 \%$ e os Estados e Municípios no mínimo 25\% da receita arrecadada com impostos. O novo parágrafo $7^{\circ}$, ao dispor sobre esses recursos, resolve uma questão pendente na legislação: tais recursos, bem como aqueles referentes à contribuição social do salário-educação, recolhido pelas empresas, não podem ser aplicados no pagamento de aposentadorias e pensões.

O parágrafo $8^{\circ}$, introduzido pela recente Emenda Constitucional, aparentemente ocasiona uma situação interessante e que poderia originar dúvidas quanto a sua aplicação, ao menos no âmbito da União Federal. Ocorre que a Emenda Constitucional n. 95/2016 inaugurou o Novo Regime Fiscal e impôs limites às despesas primárias do orçamento público 
federal, definindo que seus reajustes deverão se dar pela inflação, notadamente pelo Índice Geral de Preços ao Consumidor Amplo (IPCA), durante vinte exercícios financeiros, a partir de 2017.

Para as despesas com educação (e com saúde), essa forma de cálculo passou a viger a partir de 2018, nos termos da referida Emenda Constitucional. Assim, para a confecção da lei orçamentária anual, o parâmetro deixa de ser o percentual estabelecido pelo artigo 212 da Constituição Federal, isto é, os $18 \%$ da receita de impostos para a União, e passa a ser o mero reajuste inflacionário, independentemente de ter havido evolução na arrecadação. Isto, aparentemente, induz à suspensão da eficácia desse dispositivo constitucional, como sugere Karnopp (2020, p. 117) em seu estudo:

\begin{abstract}
Por esse ângulo, um dos pontos mais discutidos no tocante ao Novo Regime Fiscal se refere aos efeitos do estabelecimento de limites máximos de gastos com políticas de saúde e educação. A Emenda Constitucional reserva o artigo 110 para tratar do tema, quando estabelece os mesmos critérios de correção (pelos índices da inflação), a partir de 2018 [...]. Conforme afirmamos, essa regra suspendeu as anteriormente vigentes, tanto a que trata do custeio da saúde (artigo 198, parágrafo $2^{\circ}$, I, da Constituição Federal) quanto a que se refere ao custeio da educação (artigo 212, caput, da Constituição Federal), obrigando, no entanto, a União a aplicar os mesmos valores dos anos anteriores, apenas corrigidos pela variação da inflação, destinandose o excedente arrecadado ao pagamento da dívida pública.
\end{abstract}

Não obstante, o parágrafo $8^{\circ}$ introduzido no artigo 212 pela Emenda Constitucional n. 108/2020 estabelece que, em caso de extinção ou substituição dos impostos a que se refere o caput, os percentuais desse artigo serão redefinidos para que os recursos destinados à manutenção e desenvolvimento do ensino se mantenham no mesmo patamar ${ }^{1}$. O dispositivo poderia parecer inócuo diante do limite de gastos imposto pelo Novo Regime Fiscal, que deixa de observar tais percentuais, ao menos no caso da União.

Atento a essa questão, o legislador constitucional alterou o texto do inciso I do parágrafo $6^{\circ}$ do artigo 107 do ADCT, que integra as regras do Novo Regime Fiscal, para excluir dos limites individualizados da despesa primária as complementações a que se referem os incisos IV e V do caput do novo artigo 212-A, isto é, a complementação dos fundos estaduais e municipais pela União, como será adiante descrito.

\footnotetext{
${ }^{1}$ Entende-se que a fixação de novos percentuais, ainda que genericamente prevista sua possibilidade, não poderá ser estabelecida por outra via que não a alteração constitucional, tendo em vista que se encontram estabelecidos na Constituição Federal.
} 
Ainda, a previsão de redefinição de percentuais no caso de extinção ou substituição de impostos foi uma ação prudente do legislador constitucional, tendo em vista que, no momento da promulgação da Emenda Constitucional n. 108/2020, tramita no Congresso Nacional a Proposta de Emenda à Constituição (PEC) cujo objeto é a reforma tributária. Desse modo, a atual redação do parágrafo $8^{\circ}$ do artigo 212 realiza um esforço para assegurar que o financiamento da educação básica não seja prejudicado pela futura legislação tributária brasileira.

A introdução do artigo 212-A na Constituição Federal pode ser considerando um avanço em relação ao financiamento da educação básica em alguns pontos. O primeiro deles se refere ao fato de tornar o FUNDEB permanente e não apenas transitório, como eram o FUNDEF e o próprio FUNDEB em sua primeira versão.

Nessa linha, o caput do artigo determina aos Estados e Municípios a destinação de parte dos $25 \%$ da receita de impostos estabelecida no artigo 212 à manutenção e desenvolvimento do ensino e à remuneração condigna dos profissionais da educação, mediante algumas disposições, das quais a primeira (inciso I) é a instituição de fundos de natureza contábil, em cada Estado e no Distrito Federal, para a distribuição de recursos e responsabilidades entre estes e os Municípios.

Esses fundos, segundo o novo regramento (artigo 212-A, II, da Constituição Federal), serão compostos por $20 \%$ dos impostos sobre transmissão causa mortis e doação (ITCMD), sobre a circulação de mercadorias e prestação de serviços de transporte interestadual e intermunicipal e comunicação (ICMS) e sobre propriedade de veículos automotores (IPVA), todos de competência estadual. Além disso, incidirão, também sobre os $20 \%$ que a União transferirá aos Estados e ao Distrito Federal referentes à arrecadação do imposto federal que poderá ser criado por lei complementar (imposto residual).

Quanto aos Municípios, estes destinarão 20\% dos recursos provenientes das seguinte transferências constitucionais: da arrecadação do imposto sobre propriedade territorial rural (ITR) dos imóveis situados em seu território, do percentual correspondente à transferência do imposto sobre a propriedade de veículos automotores (IPVA) licenciados no Município e do percentual correspondente à transferência do imposto sobre a circulação de mercadorias e prestação de serviços de transporte interestadual e intermunicipal e comunicação (ICMS).

Além desses recursos, será destinado ao FUNDEB o mesmo percentual (20\%) sobre as transferências da União ao Fundo de Participação dos Estados e do Distrito Federal e ao 
Fundo de Participação dos Municípios, provenientes da arrecadação federal de imposto sobre renda e proventos de qualquer natureza (IR) e sobre produtos industrializados (IPI) e $20 \%$ sobre o valor entregue pela União aos Estados e ao Distrito Federal referente à arrecadação sobre produtos industrializados (IPI), proporcionalmente ao valor das respectivas exportações.

A Emenda Constitucional também estabelece que esses recursos sejam distribuídos entre os Estados e Municípios de modo proporcional ao número de alunos das etapas e modalidades da educação básica nos âmbitos de atuação prioritária de cada ente federado, determinados na Constituição Federal (os Municípios no ensino fundamental e na educação infantil e o Estados e o Distrito Federal, no ensino fundamental e médio). Os parâmetros desse cálculo foram delegados à lei ordinária, que considerará, entre outros aspectos, o nível socioeconômico dos alunos e a disponibilidade de recursos vinculados à educação, além do potencial de arrecadação tributária de cada ente federado. Há, portanto, uma preocupação em corrigir distorções no atual modelo de distribuição de recursos do FUNDEB, a qual leva em conta a situação financeira e a capacidade de destinação de verbas de cada ente federado.

Outro aspecto relevante do Novo FUNDEB é o que se refere à complementação da União dos fundos, que passa a ser de $23 \%$, substituindo os $10 \%$ vigentes até o final de 2020 . $\mathrm{O}$ artigo 212-A, inciso V, estabelece os parâmetros de distribuição dessa complementação: (a) $10 \%$ irão para cada Estado ou Distrito Federal cujo valor anual por aluno (VAAF) não alcançar o mínimo definido nacionalmente; (b) 10,5\% serão destinados às redes públicas de ensino municipal, estadual ou distrital quando o valor anual total por aluno (VAAT) não alcançar o mínimo definido nacionalmente, sendo que metade desses recursos deverão ser destinados à educação infantil; e (c) 2,5\% serão atribuídos às redes públicas que lograrem evoluir em indicadores de atendimento e melhoria da aprendizagem com redução das desigualdades, nos termos do sistema nacional de avaliação da educação básica.

A implementação dessa complementação pela União será progressiva, sendo que esses percentuais serão plenamente atingidos em 2026. O ADCT teve alterada a redação do seu artigo 60, para estabelecer os percentuais anuais dos recursos provenientes da referida complementação, que ficaram assim estabelecidos: em 2021, 12\%; em 2022, 15\%; em 2023, 17\%; em 2024, 19\%; em 2025, 21\%; e, a partir de 2026, 23\%. O mesmo dispositivo do ADCT também prevê os percentuais dos recursos correspondentes às subdivisões dessa complementação, que serão plenamente implementados no mesmo exercício. 
Por fim, as regras do Novo FUNDEB, em atenção ao princípio da valorização dos profissionais do magistério, aumentam de $60 \%$ para $70 \%$ a destinação dos recursos de cada fundo para a remuneração dos profissionais da educação básica em efetivo exercício, com algumas ressalvas em seu texto (artigo 212-A, XI, da Constituição Federal). Ao ordenar o emprego dos recursos para o pagamento de pessoal em efetivo exercício, esse dispositivo parece dialogar com o novo parágrafo $7^{\circ}$, do artigo 212 , que veda sua aplicação no pagamento de aposentadorias e pensões.

A partir da análise dos dispositivos da Emenda Constitucional n. 108/2020, recentemente aprovada, pode-se verificar a progressividade do financiamento da educação básica pública nos pontos aqui suscitados. Resta aguardar sua regulamentação infraconstitucional e, finalmente, sua operacionalização em cada rede de ensino, para aferir os resultados.

\section{CONCLUSÃO}

A análise do percurso histórico da legislação sobre o financiamento da educação pública brasileira, inicialmente apenas do ensino fundamental e, após, da educação básica, revela uma trajetória de progressividade.

O próprio FUNDEF, instituído pela Emenda Constitucional n. 14/1996, já constituiu um avanço em relação à previsão genérica de vinculação de recursos, no artigo 212 da Constituição Federal, ao considerar o ensino fundamental como relevante etapa de escolarização da população. O grande papel do FUNDEF, portanto, foi de subvincular parte desses recursos para alocá-los em políticas educacionais para o ensino fundamental e, também, para a valorização dos professores.

Com o passar dos anos e ao verificar-se a insuficiência do modelo adotado pelo FUNDEF, a primeira edição do FUNDEB pela Emenda Constitucional n. 53/2006 passou a abranger todos os níveis da educação básica, da educação infantil ao ensino médio, e ampliou a participação da União com recursos financeiros nos fundos contábeis, mediante o estabelecimento de regras mais claras para tal.

O Novo FUNDEB, instituído pela Emenda Constitucional n. 108/2020, conforme demonstrado, aparenta maiores avanços em relação aos fundos anteriores, conforme buscouse demonstrar ao longo do texto. Em síntese, reforçou o direito fundamental ao acesso à 
educação e à aprendizagem ao longo da vida, como princípio do ensino; tornou o FUNDEB um instrumento permanente da educação básica, em nível constitucional; aumentou significativamente (mais que o dobro) a complementação da União nos fundos contábeis instituídos nos Estados e no Distrito Federal; e ampliou para 70\% a destinação de recursos para o pagamento dos profissionais da educação básica.

Conclui-se, portanto, que o Novo FUNDEB é um instrumento que vai ao encontro do que dispõe o PIDESC, como obrigação dos Estados, da progressividade na concretização dos direitos econômicos, sociais e culturais, notadamente o da educação. Ainda que a Emenda Constitucional que o institui não veicule, em sua maioria, conteúdo de direito fundamental, o financiamento do direito à educação básica é fator que não pode deixar de ser considerado ao avaliar a progressividade das políticas voltadas a concretizar esse direito.

\section{REFERÊNCIAS}

ABRAMOVICH, Victor; COURTIS, Christian. Direitos sociais são exigíveis. Tradução de Luis Carlos Stephanov. Porto Alegre: Dom Quixote, 2011. 311 p.

BRASIL. [Constituição (1988)]. Constituição da República Federativa do Brasil.

Disponível em: http://www.planalto.gov.br/ccivil_03/Constituicao/Constituicao.htm. Acesso em: 28 ago. 2020.

BRASIL. [Constituição (1988)]. Ato das Disposições Constitucionais Transitórias.

Disponível em: http://www.planalto.gov.br/ccivil_03/constituicao/constituicao.htm. Acesso em: 28 ago. 2020.

BRASIL. Decreto n. 591, de 6 de julho de 1992. Atos Internacionais. Pacto Internacional sobre Direitos Econômicos, Sociais e Culturais. Promulgação. Disponível em: http://www.planalto.gov.br/ccivil_03/decreto/1990-1994/d0591.htm. Acesso em: 24 abr. 2020.

BRASIL. Decreto n. 678, de 6 de novembro de 1992. Promulga a Convenção Americana sobre Direitos Humanos (Pacto de São José da Costa Rica), de 22 de novembro de 1969. Disponível em: http://www.planalto.gov.br/ccivil_03/decreto/D0678.htm. Acesso em: 24 abr. 2020.

BRASIL. Emenda Constitucional n. 14, de 12 de setembro de 1996. Modifica os arts. 34, 208, 211 e 212 da Constituição Federal e dá nova redação ao art. 60 do Ato das Disposições constitucionais Transitórias. Disponível em: http://www.planalto.gov.br/ccivil_03/constituicao/Emendas/Emc/emc14.htm. Acesso em: 19 abr. 2020. 
BRASIL. Lei n. 9.394, de 20 de dezembro de 1996. Estabelece as diretrizes e bases da educação nacional. Disponível em: http://www.planalto.gov.br/ccivil_03/leis/19394.htm. Acesso em: 21 abr. 2020.

BRASIL. Lei n. 9.424, de 24 de dezembro de 1996. Dispõe sobre o Fundo de Manutenção e Desenvolvimento do Ensino Fundamental e de Valorização do Magistério, na forma prevista no art. $60, \S 7^{\circ}$, do Ato das Disposições Constitucionais Transitórias, e dá outras providências. Disponível em: http://www.planalto.gov.br/ccivil_03/LEIS/L9424.htm. Acesso em: 19 abr. 2020.

BRASIL. Emenda Constitucional n. 53, de 19 de dezembro de 2006. Dá nova redação aos arts. $7^{\circ}, 23,30,206,208,211$ e 212 da Constituição Federal e ao art. 60 do Ato das Disposições Constitucionais Transitórias. Disponível em:

http://www.planalto.gov.br/ccivil_03/constituicao/Emendas/Emc/emc53.htm. Acesso em: 19 abr. 2020.

BRASIL. Lei n. 11.494, de 20 de junho de 2007. Regulamenta o Fundo de Manutenção e Desenvolvimento da Educação Básica e de Valorização dos Profissionais da Educação FUNDEB, de que trata o art. 60 do Ato das Disposições Constitucionais Transitórias; altera a Lei n o 10.195, de 14 de fevereiro de 2001; revoga dispositivos das Leis n os 9.424, de 24 de dezembro de 1996, 10.880, de 9 de junho de 2004, e 10.845, de 5 de março de 2004; e dá outras providências. Disponível em: http://www.planalto.gov.br/ccivil_03/_ato20072010/2007/lei/111494.htm. Acesso em: 19 abr. 2020.

BRASIL. Emenda Constitucional n. 108, de 26 de agosto de 2020. Altera a Constituição Federal para estabelecer critérios de distribuição da cota municipal do Imposto sobre Operações Relativas à Circulação de Mercadorias e sobre Prestações de Serviços de Transporte Interestadual e Intermunicipal e de Comunicação (ICMS), para disciplinar a disponibilização de dados contábeis pelos entes federados, para tratar do planejamento na ordem social e para dispor sobre o Fundo de Manutenção e Desenvolvimento da Educação Básica e de Valorização dos Profissionais da Educação (Fundeb); altera o Ato das Disposições Constitucionais Transitórias; e dá outras providências. Disponível em: http://www.planalto.gov.br/ccivil_03/Constituicao/Emendas/Emc/emc108.htm. Acesso em: 28 ago. 2020.

COURTIS, Christian. La prohibición de regresividad en materia de derechos sociales: apuntes introductorios. In: COURTIS, Christian (Comp.). Ni un paso atrás: la prohibición de regresividad en materia de derechos sociales. 1. ed. Buenos Aires: Del Puerto, 2006. p. 3-52.

GONZAGA, Elizete Tavares de. Atores, interesses e desafios na formulação do FUNDEB. 2017. Dissertação (Mestrado Profissional em Gestão Pública) - Universidade de Brasília, Brasília, 2017. Disponível em:

https://sucupira.capes.gov.br/sucupira/public/consultas/coleta/trabalhoConclusao/viewTrabalh oConclusao.jsf?popup=true\&id_trabalho=6083823. Acesso em: 19 abr. 2020 .

KARNOPP, Laerte Radtke. Nem um passo atrás: o direito fundamental social à educação no âmbito da União Federal frente ao Novo Regime Fiscal instituído pela Emenda Constitucional n. 95/2016. Orientadora: Maria das Graças Pinto de Britto. 2020. 177 f. Dissertação 
(Mestrado em Direito) - Faculdade de Direito, Universidade Federal de Pelotas, Pelotas, 2020.

NUNES, Alynne Nayara Ferreira. FUNDEB no Congresso: exame das propostas para um fundo a vencer em breve. In: Anais do XXIV Encontro Nacional do CONPEDI. Grupo de Trabalho Metas e Objetivos de Desenvolvimento do Milênio da ONU. Florianópolis:

CONPEDI, 2015. p. 73-93. Disponível em:

http://conpedi.danilolr.info/publicacoes/c178h0tg/091ud5at/46vBj8av45skzCvy.pdf. Acesso em: 20 abr. 2020.

NUNES, Alynne Nayara Ferreira. O FUNDEB na prática: uma análise jurídica dos desafios para a implementação de políticas públicas no Brasil. 2016. Dissertação (Mestrado em Direito) - Fundação Getúlio Vargas, São Paulo, 2016. Disponível em:

https://sucupira.capes.gov.br/sucupira/public/consultas/coleta/trabalhoConclusao/viewTrabalh oConclusao.jsf?popup=true\&id_trabalho=3608830. Acesso em: 19 abr. 2020.

RAMOS, Regina Celia; DI GIORGI, Cristiano Amaral. Do Fundef ao Fundeb: avaliando o passado para pensar o futuro: um estudo de caso no município de Pirapozinho-SP. In: Ensaio: aval. pol. públ. Educ., Rio de Janeiro, v. 19, n. 72, p. 623-650, jul./set. 2011. Disponível em: http://www.scielo.br/pdf/ensaio/v19n72/a09v19n72.pdf. Acesso em: 21 abr. 2020.

SARLET, Ingo Wolfgang. A eficácia dos direitos fundamentais: uma teoria geral dos direitos fundamentais na perspectiva constitucional. 13. ed. rev. e atual. Porto Alegre: Livraria do Advogado, 2018. 515 p.

SEPÚLVEDA, Magdalena. La interpretación del Comité de Derechos Económicos, Sociales y Culturales de la expresión "progresivamente". In: COURTIS, Christian (Comp.). Ni um paso atrás: la prohibición de regresividad en materia de derechos sociales. 1. ed. Buenos Aires: Del Puerto, 2006. p. 117-150. 